\title{
XXXVII. Molecular frequency and molecular number
}

\section{H. Stanley Allen M.A. D.Sc.}

To cite this article: H. Stanley Allen M.A. D.Sc. (1918) XXXVII. Molecular frequency and molecular number, Philosophical Magazine Series 6, 35:208, 338-349, DOI:

$10.1080 / 14786440408635769$

To link to this article: http://dx.doi.org/10.1080/14786440408635769

曲 Published online: 08 Apr 2009.

Submit your article to this journal

Џ Article views: 2

Q View related articles $\square$

Citing articles: 1 View citing articles 5 
when what I hold to be more correct equations of motion are used.

Nork.-At Sir Oliver Lodge's request I have calculated $m_{1}$ and $m_{2}$ for Bucherer's electron which has the same form as Lorentz's electron but keeps its volume unchanged. My results are

$$
m_{1}=m_{0}\left(1+\frac{17}{15} v^{2} / c^{2}\right), \quad m_{2}=m_{0}\left(1+\frac{31}{6 \overline{0}} v^{2} / c^{2}\right),
$$

so that

$$
\frac{1}{2} k_{1}-k_{2}=\frac{1}{20} \text {. }
$$

XXXVII. Molecular Frequency and Molecular Number. By H. Stanley Ali.en, M.A., D.Sc., University of London, King's College*.

Part I.

\section{\$1. Molecular Number.}

T THE work of Moseley on the high-frequency spectra of 1 the elements has established securely the importance of the "atomic number" of an element: that is, the number which determines the place in the periodic classification and fixes the charge carried by the central part of the atom. It is now certain that the atomic number is more fundamental than the atomic weight. Recent investigations of the atomic weight of lead of radioactive origin have shown that the value obtained for this quantity depends upon the source from which the material is derived. An interesting account of these researches has been given by Soddyt, who points out that the atomic weight as ordinarily understood is not the unique quantity hitherto supposed. In the future increasing importance will be attached to the atomic number. It is the conviction of the present author that this will prove true not only in connexion with the properties of the chemical elements but also in dealing with compounds. In the latter case it is convenient to introduce the term "molecular number" to signify the sum of the positive charges carried by the atomic nuclei contained in the molecule. Thus when a molecule contains $a$ atoms of an element $\mathbf{A}, b$ atoms of $\mathbf{B}$, $c$ atoms of $\mathrm{C}$, so that its chemical formula is $\mathrm{A}_{a} \mathrm{~B}_{b} \mathrm{C}_{c}$, the molecular number $\mathrm{N}=a \mathrm{~N}_{a}+b \mathrm{~N}_{b}+c \mathrm{~N}_{c}$, where $\mathrm{N}_{a}, \mathrm{~N}_{b}, \mathrm{~N}_{c}$ are the atomic numbers of the component elements. For

* Communicated by the Author.

† Royal Institution Lecture, 'Nature,' vol. xcix. p. 414 (1917). 
example, the molecular number of water $\left(\mathrm{H}_{2} \mathrm{O}\right.$, hydrol $)$ is $10^{*}$, for the nuclear charge of hydrogen is 1 , and of oxygen is 8 .

It may be remarked that the molecular number is usually oven. This arises from the fact that when the valency is odd, the atomic number is usually odd also. But in the case of an element such as copper, which may be either univalent or divalent, or in the case of some of the metals of the eighth group, the molecular number may be odd.

In former papers $\dagger$ it has been shown that simple relations exist between the atomic number of an element and the characteristic frequency deduced from observations of the specific heat in the solid state. In the present communication similar results are found in connexion with the molecular number of a compound and its characteristic frequency. So far as the writer is aware, this is the first attempt to establish a relationship involving molecular number, previous work in different branches of physics having been restricted to considerations of atomic number only.

\section{§2. Characteristic Molecular Frequency.}

At high temperatures the law as to the specific heat of compounds enunciated by Joule $\ddagger$ and verified by Kopp § shows that, as the specific heat is then mainly additive, the heat energy arises for the most part from the vibrations of the individual atoms $\|$. At sufficiently high temperatures the vibrational energy of each atom approaches the value $3 \mathrm{RT}$. At low temperatures, on the other hand, Nernst T supposes that the vibrations of the molecules play a more important part than the vibrations of the atoms in the molecule. In the case of regular monatomic solids Debye has deduced an

* This fact is probably at the bottom of the remarkable numerical relations involving powers of 10 , pointed out by the author in a paper read before the Physical Society of London (Proceedings, vol, xxvii. p. 425,1915 ). It was shown that there must be a numerical connexion between the unit of length and the unit of mass in the C.G.S. system, "and there is no reason why it should not involve the number 10." This negative statement may now be changed to a positive one. There is a reason, in the constitution of water itself, why the number 10 should be introduced.

† H. S. Allen, Proc. Roy. Soc. vol. xciv. p. 100 (1917); Phil. Mag. vol. xxxiv. p. 478, p. 488 (1917).

† Joule, Phil. Mag. [3] vol. xxv. p. 334 (1844).

$\S$ Kopp, Lieb. Ann. vol. iii. pp. 1 \& 289 (1864).

If $C f$. Sutherland, Phil. Mag. [5] vol. xxxii. p. 550 (1891).

I Nernst, Dortväge iiber die Kinetische Theorie, p. 79 (1914). 'The Theory of the Solid State,' p. 81 (1914). 
expression for the specific heat, $\mathrm{C}_{v}$, which is reduced, at sufficiently low temperatures, to a simple law of proportionality between $\mathrm{C}_{v}$ and $\mathrm{T}^{3}$. That this is also true for certain regular polyatomic substances has been shown experimentally by Eucken and Schwers* in the case of fluorite, $\mathrm{CaF}_{2}$, and pyrites, $\mathrm{FeS}_{2}$. Thus it would appear that near the absolute zero the forces uniting the atoms in the molecule are sufficiently great, as compared with the forces uniting the molecules, to compel the individual atoms to follow the movements of the molecule of which each forms a part. At low temperatures the specific heat can be represented by Debye's formula assuming a single characteristic frequency. At higher temperatures Nernst introduces one or more Einstein terms, with appropriate characteristic frequencies, to include the vibrations of the atoms in the molecule. It will be shown that the characteristic frequency, $\nu$, for the molecular movement conforms to the relation previously found to hold for the elements, viz.

$$
\mathrm{N} \nu=n \nu_{\mathrm{A}} \text { or } \mathrm{N} \nu=\left(n+\frac{1}{2}\right) \nu_{\mathrm{A}},
$$

where $\mathrm{N}$ is now the molecular instead of the atomic number, $\boldsymbol{n}$ is an integer, and $\nu_{\mathrm{A}}$ is a fundamental frequency having $a$ value very near to $21 \times 10^{12} \mathrm{sec}^{-1}$. The term "frequency number" is suggested to denote the numerical factor, $n$ or $n+\frac{1}{2}$.

It would, of course, be possible to avoid the introduction of the fraction $\frac{1}{2}$ by introducing a fundamental frequency which is $\frac{1}{2}$ that just quoted, but as the number of cases requiring the fractional value is comparatively small, it seems better to retain for the present the larger value for $\nu_{\Lambda}$.

\section{§ 3. Characteristic Frequency from Specific Heat.}

For a small number of compounds low-temperature measurements are available, and the characteristic frequency can be deduced from the specific heat. In 1912 Nernst and Lindemann $\dagger$ published observations on the specific heat of rock-salt and sylvin at temperatures down to $22^{\circ} \mathrm{K}$. For $\mathrm{NaCl}$ the characteristic frequency, $\nu$, was determined by the equation $\beta \nu=287 \cdot 3$, whilst for $\mathrm{KCl} \beta \nu=217 \cdot 6$, where $\beta=4 \cdot 78 \times 10^{-11}$. From these results we find the value of $\mathrm{N} \nu$ for rock-salt to be $8 \times 21.0 \times 10^{12}$, whilst for sylvin it is nearly the same, $8 \times 20.5 \times 10^{12}$. In his address on the Kinetic Theory Nernst gives different values for the Debye

* Eucken and Schwers, Ber. deutsch.phys. Gesell. vol. xv. p. 578 (1913).

$\dagger$ Preuss. Alkad. Berlin, p. 1160 (1912). 
term which is predominant at low temperatures. For $\mathrm{NaCl}$ he finds $\beta \nu=229$, which would require $\mathrm{N}_{\nu}=6 \frac{1}{2} \times 20.6 \times 10^{12}$. As Lindemann's formula gives a smaller value (215) for $\beta v$, it may be suspected that the true value for $\mathrm{N} \nu$ at very low temperatures is $6 \times 21 \times 10^{12}$. This is supported by the value for $\mathrm{KCl}$, for which Nernst gives $\beta \nu=166$, so that $\mathrm{N} \nu=6 \times 20.8 \times 10^{12}$. The change in the frequency number from 8 to 6 must be attributed to the introduction of the Einstein term, and points to the relation $N \nu=n \nu_{\mathrm{A}}$ being obeyed by the corresponding frequency. This is actually found to be the case, as is shown in a separate paper by the writer.

Nernst also gives values for the characteristic frequency of chloride of mercury and chloride of silver. For $\mathrm{HgCl}$ $\beta \nu=115$, from which we find $N \nu=11 \times 21.2 \times 10^{12}$, and for $\mathrm{AgCl} \beta \nu=102$, giving $\mathrm{N} \nu=6 \frac{1}{2} \times 21.0 \times 10^{12}$.

Experiments by Eucken and Schwers* which are believed to be very accurate give the characteristic frequency for two compounds containing three atoms in the molecule. For fluorite $\left(\mathrm{CaF}_{2}\right) \beta \nu=474$, resulting in $\mathrm{N} \nu=18 \times 20.9 \times 10^{12}$. For pyrites $\left(\mathrm{FeS}_{2}\right) \beta \nu=645$, and as $\mathrm{N}=58$ the product $\mathrm{N} \nu$ is so large $\left(782.6 \times 10^{12}\right)$ that it is difficult to be certain of the value to be assigned to $n$. If $n=37$ the product $\mathrm{N} \nu=37 \times 21 \cdot 2 \times 10^{12}$; if, as is more probable, $n=36$ the product $\mathrm{N} \nu=36 \times 21.8 \times 10^{12}$.

Euckent found for carbon dioxide $\left(\mathrm{CO}_{2}\right)$ in the solid state $\beta \nu=119$, giving $N \nu=2 \frac{1}{2} \times 21.9 \times 10^{12}$. This is of interest as indicating that the rule applies in the case of non-metallic compounds.

\section{§4. Characteristic Frequency from Lindemann's Formula.}

For the majority of compounds no measurements of the specific heat at low temperatures have been made, and in such cases it is necessary to have recourse to some more or less empirical formula such as that of Lindemann. This formula gives

$$
\nu=3.08 \times 10^{12} \sqrt{ }\left(\mathrm{T}_{s} / \mathrm{MV}^{\frac{\xi}{3}}\right),
$$

where $\mathrm{T}_{s}$ denotes the melting-point, $\mathrm{M}$ the molecular weight, and $\mathrm{V}$ the molecular volume.

It is easy to understand that the frequency calculated in this way may not be identical with the frequency determined from the specific heat at low temperatures, for the

* Eucken \& Schwers, D. P. G. V. vol. xv. p. 578 (1913).

† Eucken, D. P. G. V. vol. xviii. p. 4 (1916).

Phil. Mag. S. 6. Vol, 35. No. 208. April 1918. 2 B 
molecule of the solid at or near the melting-point may not have the same constitution as the molecule near the absolute zero of temperature. The frequency as given by Lindemann's formula must be taken to represent the characteristic frequency the substance would take at low temperatures, on the assumption that the molecular structure remained unchanged in cooling from the melting-point to the absolute zero. If either polymerization or dissociation occur in the process of cooling, then a change in the characteristic frequency is to be anticipated.

A definite decision as to whether the relation between $\mathrm{N}$ and $\nu$ is exact or only approximate cannot be reached until further accurate determinations of the specific heat of compounds at very low temperatures are available. Empirical formulæ, such as that of Lindemann, may be employed for the evaluation of $\nu$, but it must be remembered that such formulæ generally give only approximations to the true value, and therefore cannot furnish a decisive test. It has been suggested that to render Lindemann's formula accurate an additional factor is required depending upon the relation between the molecular volume at absolute zero and that at the melting-point*. It may be anticipated that the formula in its present form should give comparable results for chemical compounds of similar constitution. This would be shown by agreement between the values of $\mathrm{N} v$, or by concordant values of $\nu_{\mathrm{A}}$ : It has, in fact, been shown previously that such agreement exists in the case of similar elements, and evidence is now put forward that relations of the same kind hold for similar compounds.

It must be borne in mind in considering the results not only that Lindemann's formula is merely an approximate one, but that the numerical factor is purely empirical. Further, it is to be noticed that the molecular volume is usually found from determinations of the density made at ordinary temperatures. It might be better to employ the density of the solid near the absolute zero of temperature or at the melting-point.

The data employed for the calculation of the characteristic frequencies in the following paragraphs have been taken mainly from Nostrand's 'Chemical Annual' for 1913, which gives Tables convenient for this purpose. Kaye and Laby's 'Physical and Chemical Constants' (1911), and the Smithsonian Physical Tables (1914) have also been made use of for certain compounds. In cases where a range of values

* Cf. Sutherland, Phil. Mag. vol. xxx. p. 318 (1890); vol. xxxii. p. 524 (1891); and Grüneisen, Ann. d. Physik, vol, xxxix. p. 298 (1912), 
is given for the melting-point, the highest value quoted has been used ; similarly the largest value of the density has been taken in calculating the molecular volume.

\section{\$ 5. Inorganic Compounds (Lindemann's Formula).}

It may be pointed out in the first place that the product $\mathrm{N} \nu$ frequently has the same value for compounds which are similar in their chemical constitution and behaviour. Thus in the case of the alkali metals we find for the chlorides of sodium, potassium, and rubidium the values :-

$\mathrm{NaCl}, 123.2 \times 10^{12} ; \mathrm{KCl}, 125.8 \times 10^{12} ; \quad \mathrm{RbCl}, 124.7 \times 10^{12}$,

Similarly for the iodides of the same metals :-

NaI, $145 \cdot 2 \times 10^{12} ; \quad \mathrm{KI}, 143 \cdot 1 \times 10^{12} ; \quad \mathrm{RbI}, 145 \cdot 4 \times 10^{12}$.

Further it may be noted that the product for the iodide exceeds that for the chloride by an amount which is approximately constant, and equal to about $20 \times 10^{12}$. Similarly the difference between the product for sodium chloride $\left(123.2 \times 10^{12}\right)$ and that for lithium chloride $\left(101.6 \times 10^{12}\right)$ is $21.6 \times 10^{12}$, whilst the difference between the product for sodium iodide $\left(145.2 \times 10^{22}\right)$ and that for lithium iodide $\left(124.7 \times 10^{12}\right)$ is $20.5 \times 10^{12}$. All such relations, and their number is far too great for them to be fortuitous, may be included in the formulæ

$$
\mathrm{N}_{\nu}=n \nu_{\Lambda} \text { and } \mathrm{N}_{\nu}=\left(n+\frac{1}{2}\right) \nu_{\Lambda},
$$

where $\nu_{\mathrm{A}}$ is approximately $21 \times 10^{12} \mathrm{sec}^{-1}$.

These formulæ have now been tested for those inorganic compounds for which the necessary data are recorded, and it has been found that the number of cases in which one or other of the formulæ cannot be applied is small. It is hoped to publish details of these results later; at present it will suffice to quote the figures for two series of compounds. In Table I. are given the results for all the lithium compounds for which data are available. This element has been selected on account of the small atomic number $(\mathrm{N}=3)$ rendering the product $\mathrm{N} \nu$ comparatively small ; consequently it is not necessary to employ large values for $n$, and a more satisfactory test of the new relation can be obtained. The frequency number in the last column of the Table falls between $3 \frac{1}{2}$ and 8 , whilst the extreme values for $\nu_{\mathrm{A}}$ are $20 \cdot 1 \times 10^{12}$ sec. $^{-1}$ and $21.3 \times 10^{12}$ sec. $^{-1}$ Application of the theory of probability to the figures shows that there is only 1 chance in 282 that these results should occur by accident. 
TABle I.

Lithium Compounds.

\begin{tabular}{|c|c|c|c|c|}
\hline Name. & Formula. & N. & $\nu \times 10^{-12}$ & $\mathrm{~N} \nu \times 10^{-12}$ \\
\hline 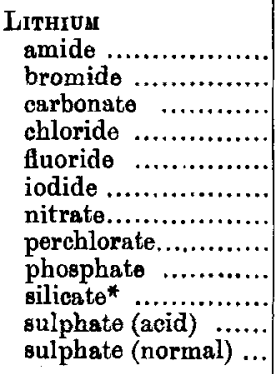 & $\begin{array}{l}\mathrm{LiNH} \\
\mathrm{LiBr} \\
\mathrm{Li}_{2} \mathrm{OO}_{3} \\
\mathrm{LiCl} \\
\mathrm{LiF} \\
\mathrm{LiI} \\
\mathrm{LiNO}_{3} \\
\mathrm{LiClO}_{4} \\
\mathrm{Li}_{3} \mathrm{PO}_{4} \cdot \mathrm{H}_{2} \mathrm{O} \\
\mathrm{Li}_{2} \mathrm{SiO}_{3} \\
\mathrm{LiHSO}_{4} \\
\mathrm{Li}_{2} \mathrm{SO}_{4}\end{array}$ & $\begin{array}{l}12 \\
38 \\
36 \\
20 \\
12 \\
56 \\
34 \\
52 \\
66 \\
44 \\
52 \\
54\end{array}$ & $\begin{array}{l}6 \cdot 073 \\
3 \cdot 234 \\
3 \cdot 435 \\
5 \cdot 079 \\
9 \cdot 207 \\
2 \cdot 227 \\
2 \cdot 821 \\
1 \cdot 742 \\
2 \cdot 345 \\
3 \cdot 756 \\
1 \cdot 636 \\
2 \cdot 680\end{array}$ & $\begin{array}{l}3 \frac{1}{2} \times 20.8 \\
6 \times 20.5 \\
6 \times 20.6 \\
5 \times 20.3 \\
5 \frac{1}{2} \times 20.1 \\
6 \times 20.8 \\
4 \frac{1}{2} \times 21.3 \\
4 \frac{1}{2} \times 20.1 \\
7 \frac{1}{2} \times 20.6 \\
8 \times 20.8 \\
4 \times 21.3 \\
7 \times 20.7\end{array}$ \\
\hline
\end{tabular}

Mean value of $\nu_{A}=20.66 \times 10^{12}$.

In Table II. are recorded the figures for the chlorides of the alkali metals, and the monochlorides of copper and silver. No data have been obtained for aurous chloride. The probability calculated in the same way as for Table $\mathrm{I}$. is about 1/18. It will be noticed, however, that all the frequency numbers in Table II. are integers. The probability that this shonld be the case is about $1 / 2000$.

TABLE II.

Monochlorides of the Metals of Group I.

\begin{tabular}{|c|c|c|c|}
\hline Formula. & N. & $\nu \times 10^{-12}$ & $\mathrm{~N} \nu \times 10^{-12}$ \\
\hline 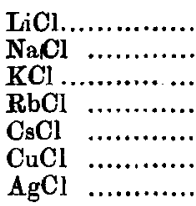 & $\begin{array}{l}20 \\
28 \\
36 \\
54 \\
72 \\
46 \\
64\end{array}$ & $\begin{array}{l}5 \cdot 079 \\
4 \cdot 401 \\
3 \cdot 493 \\
2 \cdot 310 \\
2 \cdot 065 \\
2 \cdot 726 \\
2 \cdot 343\end{array}$ & $\begin{array}{l}5 \times 20.3 \\
6 \times 20.5 \\
6 \times 20.9 \\
6 \times 20.8 \\
7 \times 21.2 \\
6 \times 20.9 \\
7 \times 21.4\end{array}$ \\
\hline
\end{tabular}

Mean value of $\nu_{\Lambda}=20.86 \times 10^{12}$.

In view of the fact that so many other inorganic compounds as well show fair agreement with the proposed relation, it is hardly possible to doubt that it must give at least a close approximation to the truth.

* The melting-point of lithium silicate is given as a standard temperature $\left(1201^{\circ}\right)$ in the Smithsonian Physical Tables. 
One point of interest may be mentioned. Inorganic compounds which contain water of crystallization conform to the general rule. In some cases the frequency number of the dehydrated salt is the same as that of the hydrated compound. Thus for sodium sulphate $\left(\mathrm{Na}_{2} \mathrm{SO}_{4}\right)$ the value of $\mathrm{N} \nu$ is $8 \times 20^{\circ} 4 \times 10^{12}$, før the hydrated salt $\left(\mathrm{Na}_{2} \mathrm{SO}_{4} \cdot 10 \mathrm{H}_{2} \mathrm{O}\right)$ it is $8 \times 20.6 \times 10^{12}$. In other cases there is a change in the frequency number. An example is afforded by calcium nitrate - the anhydrous salt $\left(\mathrm{Ca}\left(\mathrm{NO}_{3}\right)_{2}\right)$ gives for the product $\mathrm{N}_{\nu}$ the value $6 \frac{1}{2} \times 21 \cdot 3 \times 10^{12}$, whilst the hydrated compound $\left(\mathrm{Ca}\left(\mathrm{NO}_{3}\right)_{2} .4 \mathrm{H}_{2} \mathrm{O}\right)$ gives $4 \times 21.5 \times 10^{12}$.

A comparison between the results obtained from the specific heat at low temperatures and those found by calculation from Lindemann's formula is only possible in a few cases.

TABLE III.

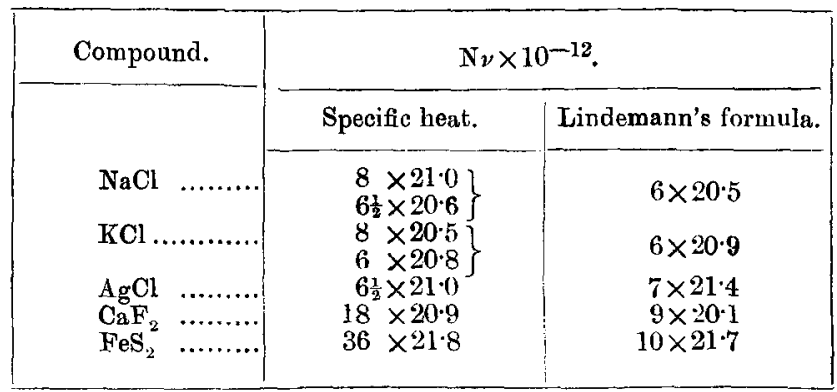

It is curious that there should be such a large difference between the two values of the frequency numbers for calcium fluoride and iron disulphide. Interpreted according to the theory of Nernst, this may indicate that for these compounds the contribution to the specific heat arising from the internal vibrations of the molecule forms an important part of the whole.

\section{§6. Organic Compounds (Lindemann's Formula).}

Chemists have not, as a rule, devoted great attention to the determination of the density of organic compounds in the solid state. On examining such a Table as that given in the 'Chemical Annual' it will be found in general that where the density of the solid is recorded, the melting-point is wanting and vice versa. Amongst the results available up to the present time are to be found many suggestive crossrelationships between the values of $\mathrm{N} \nu \times 10^{-12}$, in which a number approximating to 21 or $\frac{1}{2} \times 21$ is of frequent occurrence. This is illustrated for some aliphatic derivatives in the following Table. 
TABLE IV.

\begin{tabular}{|c|c|c|c|}
\hline Name. & Formula. & N. & $\mathrm{N} \nu \times 10^{-12}$ \\
\hline $\begin{array}{l}\text { Maleic anhydride } \ldots . . \\
\text { Succinic anhydride... } \\
\text { Malic acid }(l) \ldots \ldots \ldots \ldots \\
\text { Oxalic acid ............. } \\
\text { Maleic aoid ............. } \\
\text { Citric acid ............ } \\
\text { Tartaric acid } \ldots \ldots \ldots \ldots\end{array}$ & $\begin{array}{l}<(\mathrm{CH} \cdot \mathrm{OO})_{2}>\mathrm{O} \\
<(\mathrm{CH} \cdot \mathrm{CO})_{2}>\mathrm{O} \\
\mathrm{CO}_{2} \mathrm{H} \cdot \mathrm{CH}{ }_{2} \cdot \mathrm{CHOH} \cdot \mathrm{OO}_{2} \mathrm{H} \\
\mathrm{CO}_{2} \mathrm{H} \cdot \mathrm{CO}_{2} \mathrm{H}+2 \mathrm{H}_{2} \mathrm{O} \\
\mathrm{CO}_{2} \mathrm{H} \cdot \mathrm{CH}_{2}: \mathrm{OH} \cdot \mathrm{CO}_{2} \mathrm{H} \\
\left(\mathrm{CO}_{2} \mathrm{H} \cdot \mathrm{CH}\right)_{2} \mathrm{O}(\mathrm{OH}) \mathrm{OO} \mathrm{H}+\mathrm{H}_{2} \mathrm{O} \\
\mathrm{CO}_{2} \mathrm{H}[\mathrm{CH}(\mathrm{OH})]_{2} \mathrm{CO}_{2} \mathrm{H}\end{array}$ & $\begin{array}{r}50 \\
52 \\
70 \\
66 \\
60 \\
110 \\
78\end{array}$ & $\begin{array}{l}60 \cdot 17 \\
70 \cdot 56 \\
82 \cdot 11 \\
82 \cdot 24 \\
82 \cdot 42 \\
93 \cdot 71 \\
93 \cdot 79\end{array}$ \\
\hline
\end{tabular}

Here the characteristic difference is found between the two anhydrides; the three dibasic acids, malic, oxalic, and maleic, have a common value for the product but different values for $\mathrm{N}$; and citric acid (a monohydroxy tribasic acid) and tartaric acid (a dihydroxy dibasic acid) have the same value for $\mathrm{N} \nu \times 10^{-12}$, but a value exceeding the previous common value by the characteristic difference.

Data are available for a larger number of aromatic derivatives, and amongst these compounds many interestiug correspondences occur. In Table V. are given the results for a number of hydroxyl derivatives containing the benzene ring, and in Table VI. some of the halogen derivatives of benzene in which the two substituted groups occupy the para position.

TABLE V.

\begin{tabular}{|c|c|c|c|}
\hline Name. & Formula. & $\mathbf{N}$ & $\mathrm{N} \nu \times 10^{-12}$ \\
\hline 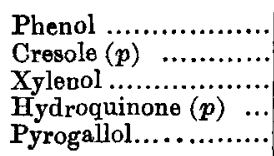 & $\begin{array}{l}\mathrm{C}_{6} \mathrm{H}_{5} \mathrm{OH} \\
\mathrm{CH}_{3}: \mathrm{C}_{6} \mathrm{H}_{4} \mathrm{OH} \\
\left(\mathrm{OH}_{3}\right)_{2} \mathrm{O}_{6} \mathrm{H}_{3} \mathrm{OH} \\
\mathrm{C}_{6} \mathrm{H}_{4}(\mathrm{OH})_{2} \\
\mathrm{C}_{6} \mathrm{H}_{3}(\mathrm{OH})_{3}\end{array}$ & $\begin{array}{l}50 \\
58 \\
66 \\
58 \\
66\end{array}$ & $\begin{array}{l}63 \cdot 29 \\
64 \cdot 23 \\
72 \cdot 84 \\
82 \cdot 07 \\
82 \cdot 52\end{array}$ \\
\hline
\end{tabular}

Table VI.

\begin{tabular}{|c|c|c|c|}
\hline Name. & Formula. & N. & $N \nu \times 10^{-12}$ \\
\hline $\begin{array}{l}\text { Chlor phenol } \ldots . . . \ldots \\
\text { Dichlor benzene ....... } \\
\text { Chlor nitrobenzene ... } \\
\text { Brom phenol ......... } \\
\text { Dibrom benzene ...... } \\
\text { Brom nitrobenzene ... }\end{array}$ & $\begin{array}{l}\mathrm{ClC}_{6} \mathrm{H}_{6} \mathrm{OH} \\
\mathrm{O}_{6} \mathrm{H}_{4} \mathrm{O}_{2} \\
\mathrm{ClO}_{6} \mathrm{H}_{4} \mathrm{NO}_{2} \\
\mathrm{BrC}_{6} \mathrm{H}_{4} \mathrm{OH}^{2} \\
\mathrm{O}_{6} \mathrm{H}_{4} \mathrm{Br}_{2} \\
\mathrm{BrO}_{6} \mathrm{H}_{4} \mathrm{NO}_{2}\end{array}$ & $\begin{array}{r}66 \\
74 \\
80 \\
84 \\
110 \\
98\end{array}$ & $\begin{array}{l}68 \cdot 40 \\
69 \cdot 63 \\
78 \cdot 86 \\
79 \cdot 41 \\
88 \cdot 64 \\
89 \cdot 95\end{array}$ \\
\hline
\end{tabular}


Data are available for a number of ketones of the benzene series.

\section{TABLE VII.}

\begin{tabular}{|c|c|c|c|}
\hline Name. & Formula. & $\mathbf{N}$ & $\mathrm{N} v \times 10^{-12}$ \\
\hline $\left.\begin{array}{c}\text { Methyl-phenyl ketone } \\
\text { (aceto-phenone) ... }\end{array}\right\}$ & $\mathrm{OH}_{3} \cdot \mathrm{CO} . \mathrm{O}_{6} \mathrm{H}_{5}$ & 64 & $63 \cdot 16$ \\
\hline $\begin{array}{l}\text { Tthyl-phenyl ketone ... } \\
\text { Metbyl-benzyl ketone ... } \\
\text { Propyl-phenyi ketone ... }\end{array}$ & $\begin{array}{l}\mathrm{C}_{2} \mathrm{H}_{5} \cdot \mathrm{OO} \cdot \mathrm{C}_{6} \mathrm{H}_{5} \\
\mathrm{CH}_{3} \cdot \mathrm{CO} \cdot \mathrm{CH}_{2} \cdot \mathrm{C}_{6} \mathrm{H}_{5} \\
\mathrm{C}_{3} \mathrm{H}_{7} \cdot \mathrm{CO} \cdot \mathrm{C}_{6} \mathrm{H}_{5}\end{array}$ & $\begin{array}{l}72 \\
72 \\
80\end{array}$ & $\begin{array}{l}64 \cdot 48 \\
65 \cdot 03 \\
65 \cdot 81\end{array}$ \\
\hline
\end{tabular}

Here the values of $\mathrm{N} \nu \times 10^{-12}$, though not differing greatly for the various compounds, tend to increase slightly with the complexity of the chemical molecule, indicating the presence of a constitutive influence.

An attentive examination of the results just recorded for organic compounds will have shown that in a large number of cases the value of the product $\mathrm{N} \nu$ can be expressed in the form already employed for inorganic compounds. In other cases, however, the simple form of the relation cannot be applied successfully. The two Tables following (VIII. and IX.) contain the figures for a number of well-known aliphatic and aromatic compounds for which the relation is found to hold good.

It is noteworthy that the frequency number for organic compounds is usually small, varying from about 3 to about 5 . 'This fact may be correlated with the low melting-point of these compounds and the small atomic numbers of the constituent olements.

TABLE VIII.

Aliphatic Compounds.

\begin{tabular}{|c|c|c|c|c|}
\hline Name. & Formula. & $\mathbf{N}$ & $\nu \times 10^{-12}$ & $\mathrm{~N} \nu \times 10^{-12}$ \\
\hline Butyl carbinol (tert.) ... & $(\mathrm{CH}) \mathrm{C}, \mathrm{OH} O \mathrm{OH}$ & 50 & $1 \cdot 212$ & $3 \times 20 \cdot 7$ \\
\hline 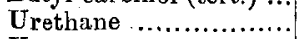 & $\mathrm{NH}_{2} \mathrm{CO}_{2} \cdot \mathrm{C}_{2} \mathrm{H}_{5}$ & 48 & 1.307 & $3 \times 20.9$ \\
\hline Urea. & $\mathrm{CO}\left(\mathrm{NH}_{2}\right)$ & 32 & $2 \cdot 243$ & $3 \frac{1}{8} \times 20.5$ \\
\hline Ethyl urea & $\mathrm{C}_{2} \mathrm{H}_{3} \mathrm{NH}^{2} \cdot \mathrm{CONH}$ & 48 & 1.500 & $3 \frac{1}{2} \times 20^{\circ} 6$ \\
\hline Ethylene iodide & $\mathrm{CH}_{2}^{2} \mathrm{I} \cdot \mathrm{CH}_{2} \mathrm{I}$ & 122 & 0.672 & $4 \times 205$ \\
\hline Iadóform ............ & $\mathrm{CHI}_{3}$ & 166 & 0.549 & $4 \frac{1}{2} \times 20.3$ \\
\hline Carbon tetrabromide ... & $\mathrm{CBr}_{4}$ & 146 & 0.703 & $5 \times 20.5$ \\
\hline Oxamide......$\ldots \ldots$ & $\mathrm{CONH}_{2} \cdot \mathrm{CONH}_{2}$ & 46 & $2 \cdot 209$ & $5 \times 20.3$ \\
\hline
\end{tabular}


TABLE IX.

Aromatic Compounds.

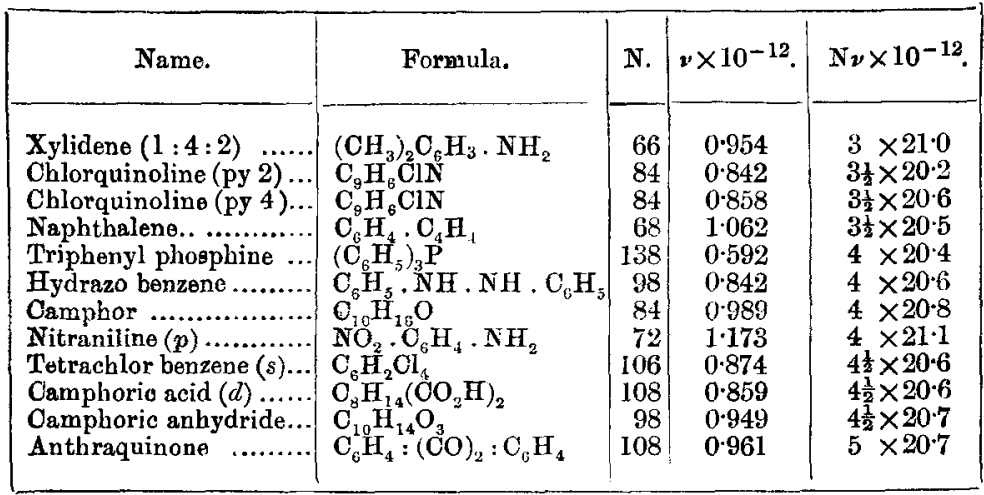

It has been mentioned already that for a considerable number of organic compounds the proposed relation, in its simple form, does not hold. One possible suggestion as to the reason for this failure will be considered in the following section.

\section{§ 7. Molecular Association in Solids.}

A question of great importance, which can only be considered briefly in this paper, is the determination of the true value of the molecular weight of a solid compound. Nernst has shown how the constitution of the molecule may be inferred from the correspondence between the molecular heat at low temperatures and the value calculated by Debye's formula. For example, he concludes that the molecule of ice is not hydrol $(\beta \nu=227)$ but dihydrol $(\beta \nu=155)$. On the first supposition we find $\mathrm{N} v=47 \cdot 5 \times 10^{12}$, which cannot be expressed as a multiple of $\boldsymbol{\nu}_{\boldsymbol{\Delta}}$, but the second supposition gives $\mathrm{N} \nu=64.8 \times 10^{12}=3 \times 21.6 \times 10^{12}$, showing good agreement with the new relation.

If, in the next place, we apply the formula of Lindemann to ice $\left(\mathrm{T}_{s}=273^{\circ} 1 \mathrm{~K}, \rho=0.917\right)$, we find that neither $\mathrm{H}_{2} \mathrm{O}$ nor $\left(\mathrm{H}_{2} \mathrm{O}\right)_{2}$ gives satisfactory agreement. When, however, we assume that the ice molecule at the melting-point is trihydrol, $\left(\mathrm{H}_{2} \mathrm{O}\right)_{3}$, we find $\mathrm{N} \nu=2 \frac{1}{2} \times 21 \cdot 4 \times 10^{12}$. The method does not give a unique determination of the degree of association, for equally good concordance is obtained by assuming that the ice molecule contains 9 groups of $\mathrm{H}_{2} \mathrm{O}$, which makes $\mathrm{N} \nu=3 \times 21.4 \times 10^{12}$.

On general grounds it seems most probable that ice at the melting-point is pure trihydrol. This was the conclusion 
reached by Sutherland*, who emphasized the fact that water crystallizes in the hexagonal system, whilst trihydrol can be represented by three linked oxygen atoms at the corner of an equilateral triangle with the six hydrogen atoms arranged symmetrically round them.

It is easy to examine the effect of association on the frequency as determined by Lindemann's formula. If $M$ denote the molecular weight of the simplest molecule, that of the associated molecule may be written $x \mathrm{M}$. The molecular volume $V$ will also be increased $x$ times. Hence the frequency, determined by the equation

$$
\nu=\frac{k}{\nabla^{\frac{1}{3}}} \sqrt{\left(\frac{\mathrm{T}}{\mathrm{M}}\right)}
$$

will be divided by $x^{\frac{1}{3}+\frac{1}{2}}=x^{\frac{5}{6}}$. The atomic number will be inereased $x$ times, and consequently the value of $\mathrm{N}_{\nu}$ will be multiplied by $x^{\frac{1}{6}}$. It is, then, a simple matter to find an integral value for $x$ so as to satisfy the relation $\mathrm{N}_{\nu}=n \nu_{\Lambda}$. As in most cases there is no independent check on the degree of association of a solid, it does not seem desirable in the present state of our knowledge to attempt to apply this method in detail.

\section{§8. Conclusion.}

In this preliminary survey of the subject of the relation between molecular frequency, $\nu$, and the molecular number, $\mathrm{N}$, it has been proved that the product $\mathrm{N} \nu$ frequently shows related values for analogous compounds. There is considerable evidence for the validity of a formula of the type $N \nu=n \nu_{A}$ in the case of most inorganic solid compounds and of a number of organic compounds. To what extent the formula is to be considered approximate can be decided only when further data as to the specific heat of solids at low temperatures are available. The physical significance of such a formula bas been discussed in an earlier paper. Perbaps the simplest interpretation that can be suggested for the "frequency number," $n$, is that it is related to the number of valency electrons concerned in imparting to the solid its crystalline structure. Further investigation on these lines may serve to throw more light on the nature of the forces connecting the molecules, and the problem of molecular association, in crystalline solids. (1910).

* Sutherland, Phil. Mag. rol. 1. p. 460 (1900); Faraday Soc. vol. vi. 